\title{
Right to Life: Improvements in the Legislation of the Russian Federation Concerning Palliative Care
}

\author{
Alsu Machmutovna Khurmatullina ${ }^{1}$, Rimma Rashitovna Amirova ${ }^{1}$ \& Olga Mikhailovna Smirnova ${ }^{2}$ \\ ${ }^{1}$ Department of Constitutional and Administrative Law, Kazan Federal University, Kazan, Russia \\ ${ }^{2}$ Department of Biomedical Ethics, Medical Law and History of Medicine, Kazan State Medical University, \\ Russia \\ Correspondence: Alsu Machmutovna Khurmatullina, RUDN University, Russia. E-mail: akm551@mail.ru
}

Received: June 9, 2019

Accepted: August 25, 2019

Online Published: August 31, 2019

doi:10.5539/jpl.v12n5p34

URL: https://doi.org/10.5539/jpl.v12n5p34

\begin{abstract}
This article raises the issues of organizing palliative care as one of the forms of implementing the right to life. The authors identify and describe the principles of palliative care. International law regulating palliative care is reviewed, along with a brief overview of the development of Russian law concerning palliative care and a list of patients who may be subject to palliative care. Special attention is given to the issue of decision-making by the patient's family. In connection with that, examples are cited for foreign models of communication between palliative care and decision science researchers, theorists, and clinicians, patients and their families for the purpose of exchanging information and studying the patients' health issues, discussing treatment options and making coordinated decisions during the life-limiting illness of patients.

The results of this research are based on using the following methods: universal dialectical method of scientific cognition, as well as general scientific methods based on it (description, analysis, synthesis, induction, deduction, comparison, analogy, generalization) and specific scientific methods (comparative law method, systematic structural method and formal law method).
\end{abstract}

Keywords: right to life, palliative care, health, constitution, international organizations, SDM

\section{Introduction}

The right to life was first formally declared and established in late XVIII century. Charles Montesquieu, an Enlightment era philosopher, stressed that all civil and political laws are "preceded by laws of nature, called that way because they solely arise from the constitution of our existence".

Until the middle of the XX century, states did not realize how fundamental is the notion of the right to life. It only became a focus of the international community after World War II. The Universal Declaration of Human Rights, passed by the UN in 1948, established (in Article 3) the inalienable natural right of the human - the right to life.

In Russia, the right to life was first proclaimed in the Declaration of Rights and Freedoms of Human and Citizen of 1991, and later written into the current Constitution of the Russian Federation. This category of utmost importance as the highest social value is a determining category for the entire Russian legal system.

This right is guaranteed by a group of legal tools specified in either the Russian Constitution or in specific regulations.

Paragraphs 1 and 2 of Article 7 of the Russian Constitution, Russia is proclaimed a social state where human health is protected by the state, and Article 41 establishes the constitutional right of each person and citizen for healthcare and medical help.

«what is closely interrelated: they have one function, the maintenance and preservation of human health» Since the second half of the XX century, among the types of medical care, the medical community identifies palliative medical care, which is a type of palliative care.

\section{Methods}

The comparative law method allowed us to identify the principles of providing palliative care.

Using the systematic structural cognition method allowed us to identify the features of palliative care regulations on the international and domestic level.

The formal law method of research was used to identify the content of such notions as palliative care, shared decision making, life limiting illness and others. 


\section{Results}

One of the central goals of palliative care is to support and assist patients and families with complex decision making; collaboration with decision scientists may provide important insights and evidence for palliative care practitioners.

Currently, developing evidence-based approaches to assist patients with life-limiting illness and their families facing multiple complex decisions over time is a palliative care research priority.

A recent National Cancer Institute report, Patient-centered Communication in Cancer Care: Promoting Healing and Reducing Suffering, identified deficits in communication around decision making across the trajectory of cancer. The main research gaps identified were the need to include discussion of alternative options such as forgoing cancer treatment, surrogate decision making, and decision making as the end of life (EOL) approaches. These problems should become a primary task of science, since it is science that should answer the questions arising from decision-making during a serious illness. Indeed, we should note that as soon as a patient is diagnosed with a life-limiting illness, their family will face the need to make many complex decisions. In foreign practice, Shared decision-making (SDM) describes a model for health communication which encourages an egalitarian approach to decision making, recognizing the skills and experience offered by all participants involved in treatment decisions. Also it has been defined as a relationship among patients, family, and one or more health professionals where the participants clearly establish the decision that needs to be made, discuss the options (including outcomes of options), elicit patients' values and preferences associated with those options, and engage patients or their surrogates, to the extent desired, in making and implementing a decision. SDM constitutes an ethical imperative to include patients and their families in health care decision making.

This is why we believe that citizens of Russian Federation need similar communicative communities, which can become the framework for establishing cooperation between palliative care and decision science researchers, theorists, and clinicians, patients and their families to exchange information and study the patients' health problems, discuss treatment options and make coordinated decisions during the life-limiting illness of patients.

\section{Discussion}

The importance of palliative care for the international community as one of the forms of implementing the right to life is evidenced by the creation of international organizations such as the Global Alliance for Palliative and Hospice Care, the European Association of Palliative Care, the International Association of Hospice and Palliative Care, and the emergence of similar associations in European, American and South East Asian countries.

The World Health Organisation (WHO) first presented its "Global Atlas of Palliative Care at the End of Life" (2014). It defines palliative care as comprehensive professional care aimed at improving a person's life when the opportunities for treatment are limited or exhausted.

The principles of palliative care are listed in a dedicated document of the European Association of Palliative Care called the White Book.

Palliative care is not limited to easing the pain, but also comprises psychological, social and spiritual support for the patient and their family. According to WHO, over 20 million terminally ill patients require palliative care each year, and unfortunately $6 \%$ of them are children. Currently only 20 countries have developed a proper system of palliative care.

The "Basic Law of Healthcare in the Russian Federation" of 1993 does not mention palliative care. The structure of the Russian healthcare system underwent a qualitative transformation in the 1990s. Deficiencies in some types of medical services provided by the state, including palliative care, were identified.

Generally, only the legislation concerning pain alleviation for such patients was developing. This was reflected in the Federal Laws "On narcotic and psychotropic substances" and "On the circulation of medical drugs". To implement these laws, the Government of the Russian Federation passed seven regulations concerning this area (including novel regulations about the use of narcotic drugs, psychotropic substances and their precursors for medical purposes); the Ministry of Healthcare and Social Development also passed a number of regulations.

A whole new stage of the organization of palliative care in Russia started on 1 January 2012, when the Federal Law No. 323-FZ "On the basics of healthcare in Russian Federation" dated 21 November 2011 took effect.

In Article 32, it describes a new type of medical care, the palliative medical care.

Part 1 of Article 36 defines it as "a group of medical interventions aimed at eliminating pain and alleviating other serious manifestations of a diseases, for the purpose of improving the quality of life of terminally ill patients". Part 2 of this article defines the conditions of such care (outpatient and inpatient), and the persons who are authorized to provide such care (medical workers who complete a course in such care).

Paragraph 4, Part 1, Article 80 of that law states that "medical organizations provide palliative medical care as part of the guaranteed national healthcare for citizens...", and "as part of the guaranteed free palliative care for 
citizens, they should be provided with medicines included into the list of vital, essential and necessary medicines in accordance with Federal Law No. 61-FZ "On the circulation of medicines" dated 12 April 2010, and with medical products required by the standards of medical care".

Part 4 of Article 83 formulates the regulations for financing the palliative medical care: these could be funds from regional budgets granted as part of local guaranteed healthcare programmes, or other sources of funds in accordance with Federal Law No. 323.

Paragraph 6 of the Order of the Ministry of Healthcare of the Russian Federation No. 187-n dated 14 April 2015 defines the patients who may be subject to palliative care - these include not only patients with various forms of malignant growth, but also patients with other incurable chronical progressive diseases and states (serious forms of dementia, patients with late-stage degenerative neural diseases and others).

In implementing these regulations, charities, funds, professional associations and government authorities (Federal Service for Surveillance in Healthcare, Social Security Fund, Ministry of Healthcare) increasingly argue for important amendments to the Federal Law of the Russian Federation "On the basics of healthcare for citizens in the Russian Federation".

The urgency of these changes is also determined by the WHO resolution WHA 67.19 "Strengthening of palliative care as a component of comprehensive care throughout the life course" (Geneva, Switzerland, 19-24 May 2014).

On 6 March 2019, Article 36 of the Federal Law "On the basics of healthcare of citizens in the Russian Federation was amended. For the first time, it specifies two types of palliative medical care - primary care (including pre-medical and medical care) and specialized care.

Now, in accordance with that law, care can also be provided at home and in outpatient conditions, and not only by medical workers, but also by social organizations in cooperation with medical workers.

\section{Findings}

These changes also required amendments to the Federal Law "On the circulation of medicines", since the expansion of forms of palliative care also expands the range of persons authorized to deal with strong painkillers. The progress of biomedical technologies today allows optimal preservation of life for patients who were previously doomed to death as of late XX century.

Despite the crisis of the modern social state, state institutions integrate qualitatively new opportunities for palliative care into the healthcare system, thus supporting the implementation of everyone's most important natural right, the right to life.

The provision of palliative care is based on the principle of respecting the decisions of patients and is directed at providing practical support for their families, particularly to overcome the loss of a family member during the illness and after the patient's death.

\section{Conclusions}

The next steps in the development of Russian legislation concerning palliative care should include:

1) regulating the specific details of providing optimal palliative care for different age groups (e.g. geriatric and underage patients);

2) adopt clinical protocols for providing various forms of palliative medical care depending on the specific circumstances of the disease;

3) expand the list of diseases that require palliative care, amending the relevant regulations of the Russian Ministry of Healthcare;

4) taking into account the expansion of the notion of the "right to life" in the modern world, the immediate goal of the state and the society in general should be not only to extend the life of critically ill patients and supporting their biological function, but also to create dignified conditions for their high-quality social and intellectual life; that will require adopting a number of regulations for inter-department cooperation between the Russian Ministry of Healthcare and Ministry of Labour;

5) as a result, the adoption of a specific Federal Law "On palliative care in Russian Federation" is unavoidable.

\section{Acknowledgments}

The work is performed according to the Russian Government Program of Competitive Growth of Kazan Federal University.

\section{References}

Act of the Supreme Soviet of the RSFSR No. 1920-1 dated 22 November 1991 "On the Declaration of Rights and Freedoms of Human and Citizen". Retrieved from http://www.consultant.ru/cons/cgi/online.cgi?req=doc\&base=LAW\&n=3788\&fld=134\&dst=100014,0\&rnd $=0.5215772401559664 \# 09926704286147734$ 
Adams, J., Drake, R., \& Wolford, G. (2007). SDM Preferences of people with severe mental illness. Psychiatr Serv., 58, 1219-1221. https://doi.org/10.1176/ps.2007.58.9.1219

Bakitas, M., Kryworuchko, J., Matlock, D. D., \& Volandes, A. E. (2011). Palliative Medicine and Decision Science: The Critical Need for a Shared Agenda To Foster Informed Patient Choice in Serious Illness. Journal of Palliative Medicine, 14(10), 1109-1116. https://doi.org/10.1089/jpm.2011.0032

Bernal, E., Marco, C., Parkins, S., Burderer, N., \& Thum, S. D. (2007). End-of-life decisions: Family views on advance directives. Am J Hospice Palliat Med., 24, 300-307. https://doi.org/10.1177/1049909107302296

Epstein, R., Street, R. Jr. (2007). Patient-Centered Communication in Cancer Care: Promoting Healing Reducing Suffering. Bethesda, MD: National Cancer Institute. https://doi.org/10.1037/e481972008-001

Khurmatullina, A. M., \& Amirova, R. R. (2018). Transformations of the Right to Health Care Content, and its Connection with the Right to Biotechnology. International Journal of Engineering \& Technology, 7(4), 267-269. https://doi.org/10.14419/ijet.v7i4.26.27934

Montesquieu, Ch. (1955). The Spirit of Laws. Selected works. M.

Murray, M. A., Miller, T., Fiset, V., O'Connor, A. M., \& Jacobsen, M. J. (2004). Decision support: Helping patients and families to find a balance at the end of life. Int $J$ Palliat Nurs., 10, 270-277. https://doi.org/10.12968/ijpn.2004.10.6.13268

Order of the Ministry of Healthcare dated 14 April 2015 No. 187n "On approving the Regulations for adult palliative care". Retrieved from http://base.garant.ru/71014388/\#friends

The White Book - a document by the European Association for Palliative Care. The Association is a non-governmental organization recognized by the European Council and created to increase awareness, knowledge and experience in the area of elderly care, to unite the national organizations for palliative care, and to create an international network for exchange information and experience. Retrieved from https://www.eapcnet.eu

Universal Declaration of Human Rights (passed by the UN General Assembly on 10 December 1948). Rossiyskaya Gazeta No. 67. 05 April 1995.

WHO Global Atlas of Palliative Care at the End of Life, World Health Organization, 2014.

\section{Copyrights}

Copyright for this article is retained by the author(s), with first publication rights granted to the journal.

This is an open-access article distributed under the terms and conditions of the Creative Commons Attribution license (http://creativecommons.org/licenses/by/4.0/). 